\title{
Experimental neurocysticercosis: absence of IL-4 induces lower encephalitis
}

\author{
Neurocisticercose experimental: ausência de IL-4 induz menos encefalite \\ Hidelberto Matos Silva ${ }^{1,2}$, Marina Clare Vinaud', Ruy de Souza Lino Júnior ${ }^{1}$
}

\begin{abstract}
Neurocysticercosis (NCC) is the most severe clinical manifestation of cysticercosis. One of the factors responsible for its symptomatology is the host inflammatory response. Therefore the influence of interleukin 4 (IL-4) on the induction of encephalitis in experimental NCC was evaluated. Methods: BALB/c (WT) and BALB/c (IL-4-KO) mice were inoculated intracranially with Taenia crassiceps cysticerci and euthanized at 7, 30, 60 and 90 days later, the encephala removed and histopathologically analyzed. Results: The absence of IL-4 induced greater parasitism. In the initial phase of the infection, IL-4-KO showed a lower intensity in the inflammatory infiltration of polimorphonuclear cells in the host-parasite interface and intra-parenquimatous edema. The IL-4-KO animals, in the late phase of the infection, showed lower intensity of ventriculomegaly, encephalitis, and meningitis, and greater survival of the parasites in comparison with the WT animals. Conclusion: The absence of IL-4 induced lower inflammatory infiltration, ventriculomegaly and perivasculitis in experimental NCC.
\end{abstract}

Keywords: neurocysticercosis; Taenia crassiceps; encephalitis; interleukin-4.

\section{RESUMO}

A Neurocisticercose (NCC) é a manifestação clínica mais severa da cisticercose, e um dos fatores responsáveis pela sintomatologia é a resposta inflamatória do hospedeiro. Desta forma avaliou-se a influência da interleucina 4 (IL-4) na indução de encefalite na NCC experimental. Métodos: Camundongos das linhagens BALB/c (WT) e BALB/C (IL-4-KO) foram inoculados intracranialmente com cisticercos de Taenia crassiceps e eutanasiados aos 7, 30, 60 e 90 dias após a infecção, os encéfalos foram removidos e analisados histopatologicamente. Resultados: A ausência da IL-4 induziu um maior parasitismo nos animais. Na fase inicial da infecção os animais IL-4-KO apresentaram menor intensidade tanto de infiltrado inflamatório de polimorfonucleares na interface parasito-hospedeiro quanto de edema intraparenquimatoso. Os animais IL-4-KO, na fase tardia, apresentaram menor intensidade de ventriculomegalia, encefalite, meningite e maior sobrevivência dos cisticercos em relação aos animais WT. Conclusão: A ausência da IL-4 induz menos infiltrado inflamatório, ventriculomegalia e perivasculite na NCC experimental.

Palavras-chave: neurocisticercose; Taenia crassiceps; encefalite; interleukin-4.

Neurocysticercosis (NCC) is the most severe clinical manifestation of cysticercosis and is responsible for up to $29 \%$ of the epilepsy cases in Latin America, India and Africa ${ }^{1,2}$. The NCC symptoms are caused by the host inflammatory response, immune response modulation, location of the parasite, evolutionary stage of the parasite, parasitic burden, as well as the mass effect induced by its growth, which results in a wide clinical and laboratory polymorphism challenging the diagnosis of this disease ${ }^{3,4}$.

Experimental models have been used as important tools in the study and comprehension of the host-parasite relationship in human cysticercosis in several locations including the neurological one $e^{5,6,7}$. The most-used parasite in the experimental models is Taenia crassiceps cysticercus due to its rapid development cycle and its antigenic similarity with $T$. solium ${ }^{7,8}$. The intraperitoneal experimental model is the most common and is very useful in the evaluation of the genetic factors involved in the host's susceptibility and resistance, with emphasis on the immunological mechanisms. The T. crassiceps intraperitoneal infection induces an initial Th1 response accompanied by large amounts of interferon-gamma, classically activated macrophages (pro-inflammatory or M1), IgG2a antibodies and interleukin-12 (IL-12) leading to a low parasitic burden. Soon afterwards there is a strong Th2 polarization due to the immunoregulatory capacity of the parasite

\footnotetext{
${ }^{1}$ Universidade Federal de Goiás, Instituto de Patologia Tropical e Saúde Pública, Goiânia Go, Brasil;

${ }^{2}$ Centro Universitário UNIRG, Faculdade de Medicina, Gurupi TO, Brasil.

Correspondence: Hidelberto Matos Silva; Centro Universitário UNIRG, Faculdade de Medicina; Av. Rio De Janeiro, 1585; 77403-090 Gurupi TO, Brasil; E-mail: hidelbertomatos@gmail.com

Conflict of interest: There is no conflict of interest to declare.

Received 02 May 2016; Accepted 31 October 2016.
} 
increasing serum levels of IgG and IgE as well as IL-4, IL-13 and IL-5, which inhibits the initial Th1 response and favors the growth of parasitic burden ${ }^{7,8,10,11}$.

The experimental models exploring the neurological location of cysticerci are described using Mesocestoides $\operatorname{corti}^{5,12,13}$ and $T$. crassiceps $^{6}$. The model carried out with $M$. corti was used to describe the role of defense cells and cytokines in the host-parasite relationship ${ }^{13}$, the expression of Toll-like receptors ${ }^{5}$, the migration of leucocytes to the central nervous system, the junction complex proteins and the immune system evasion strategies ${ }^{14}$. According to these studies, the immune response in the murine experimental model of NCC is associated with a predominant Th1 immune response directed by gamma-delta $\mathrm{T}$ lymphocytes, which arrive at the infection site at the beginning of the infection and remain in it during the whole course of the infection. These cells induce an increase in the pro-inflammatory cytokine production and a greater local cellular response ${ }^{7}$, which does not eliminate the parasite, possibly due to its evasion strategies ${ }^{14}$. Therefore there is an increase in the parasitic burden and in the inflammatory cells within extraparenchymatous areas of the encephala, such as ventricles, meninges and subarachnoid space ${ }^{13}$. It is interesting to highlight that a low parasitic burden is able to promote an initial Th1 response that is capable of eliminating the parasite ${ }^{5}$. As the infection progresses, parasites and immune cells reach the brain parenchyma, which increases the inflammation intensity and results in more severe clinical symptoms ${ }^{13}$.

Taenia crassiceps is also used as an experimental model for NCC studies due to is antigenic similarities to T. solium cysticerci $^{8,15}$. It has also already been described that T. crassiceps cysticerci are able to induce NCC in immunocompromised $^{16}$ and immunocompetent individuals ${ }^{17}$. In this model, the infected animals presented with tissue alterations and lesions such as encephalitis, perivasculitis, ventriculomegaly, ependymitis, meningitis, microgliosis accompanied by the parasite's death, and extraparenchymal and parenchymal inflammatory infiltration ${ }^{6,18}$.

Other experimental models have been proposed but instead of using $T$. crassiceps cysticerci they performed an intracranial inoculation of T. solium oncospheres in rats ${ }^{19}$ and in swine ${ }^{20}$. The rat NCC model reported that the infected animals presented with epilepsy, inflammatory infiltration, perivascular infiltrate, angiogeneses, spongy changes and mass effect in the brain tissue ${ }^{19}$. In the swine NCC model, after four months of infection, it was possible to observe calcified cysticerci surrounded by an exacerbated inflammatory response with lymphocyte infiltration and increased inflammatory markers ${ }^{20}$.

The BALB/c mice are genetically susceptible to intraperitoneal infection with $T$. crassiceps cysticerci because they present a Th2 immune profile ${ }^{7,9}$. However the immunological mechanisms associated with susceptibility or resistance of this mice lineage to T. crassiceps cysticerci are not completely understood.

The aim of this study was to describe and compare the influence of IL-4 in the encephalic inflammatory response to the experimental T. crassiceps NCC infection in two lineages of BALB/c mice - wild type (WT) and IL-4 knockout (IL-4-KO).

\section{METHODS}

\section{Maintenance of $T_{\text {. }}$ crassiceps}

The T. crassiceps cysticerci (ORF strain) have been maintained through intraperitoneal passages in female BALB/c mice $^{8}$ in the animal facility of the Tropical Pathology and Public Health Institute (IPTSP) of the Federal University of Goias (UFG) since 2002.

\section{Animals}

Two lineages of female BALB/c mice were used: conventional BALB/c also known as WT, and IL-4-KO BALB/c mice that have no gene for IL-4 production. The animals provided by the IPTSP/UFG animal facilities were eight to 12 weeks old and weighed 20 to 30 grams .

In this study the animals were divided into four groups with five mice each as follows: group 1 - WT BALB/c mice inoculated with T. crassiceps cysticerci; group 2 - WT BALB/c mice inoculated with sterile saline solution; groups 3 - IL-4-KO BALB/c mice inoculated with T. crassiceps cysticerci; and group 4 - IL-4-KO BALB/c mice inoculated with a sterile saline solution. This study was approved by the ethics committee for animal use (CEUA/UFG) protocol number 034/09.

\section{Experimental infection}

The intracranial infection of the animals was performed as described by Matos-Silva et $\mathrm{al}^{6}$. Briefly, the animals were weighed and anesthetized with $0.01 \mathrm{ml} / \mathrm{g}$ of ketamine $10 \%$ and xilazine $2 \%$ intraperitoneal injection. After trichotomy of the superior portion of the head and antisepsis with topical iodine, a longitudinal and median incision was made on the skin of the skull with a scalpel. The trepanation orifice was performed with a drill $(44.5 \mathrm{~mm} \times 2 \mathrm{~mm})$ moved by a micromotor (LB100-Beltec) in the topography of the right parietal bone at $3 \mathrm{~mm}$ from the median line (sagittal suture) and at $3 \mathrm{~mm}$ posterior to the coronal suture and with $4 \mathrm{~mm}$ of depth. The infected animals were intracranially inoculated with three to five cysticerci, following which the trepanation orifice was closed with sterile dental alginate and the incision sutured.

\section{Removal of the encephala}

At 7, 30, 60 and 90 days post inoculation (DPI) the animals were euthanized with a lethal dose of the anesthetic solution to allow the removal of the encephala. 


\section{Histopathological analysis}

After the removal, the encephala were fixed in $10 \%$ buffered formaldehyde for 24 hours. The encephala were analyzed and their macroscopic characteristics photographically documented. The macroscopic analysis considered the presence of parenchymal or extra-parenchymal cysticerci, edema, hyperemia, tissue consistency and ventriculomegaly.

Afterwards the encephala were histologically processed, in which the encephala fragments were included in paraffin. After a $5 \mu \mathrm{m}$ width microtomy the fragments were stained with hematoxilin-eosin' ${ }^{6}$.

\section{Analysis of the general pathologic processes and} classification of the cysticerci into evolutionary stages

The general pathologic processes were evaluated within the parasite, in the host-parasite interface and in the host tissue as to: presence of cysticercus, anatomic location, evolutionary stage of the cysticercus (initial - no buddings, translucent membrane and vesicular fluid; larval - presence of buddings, translucent membrane and vesicular fluid; final - no buddings, opaque membrane and vesicular fluid), ventriculomegaly, parenchymatous and perivascular edema, gliosis, meningitis, ependymitis, choroiditis, perivasculitis, microgliosis, and the profile of inflammatory infiltration cells (polymorphonuclear or mononuclear cells). The pathologic processes detected were classified in a semi-quantitative form according to the following criteria: absent (score 0), discrete - with up to $25 \%$ of area commitment (score 1), moderate - $26 \%$ to $50 \%$ of area commitment (score 2), and accentuated - more than $50 \%$ of area commitment (score 3$)^{6}$. The score attributed to each analysis was counted and used to calculate mean \pm standard deviation and the statistical analysis.

\section{Statistical analysis}

The statistical analysis was performed using the Sigma Stat 2.3 software. All variables were tested for normal distribution and homogenous variation. If they presented non-normal distribution, the variables were analyzed by the nonparametric Mann-Whitney test. The differences were considered significant when $\mathrm{p}<0.05$.

\section{RESULTS}

\section{Macroscopic alterations}

The macroscopic alterations were more evident after 30 DPI in BALB/c WT animals, which presented with hyperemia, and decreased encephalic consistency accompanied by intraventricular cysticerci. Most of these animals presented with ventriculomegaly, adjacent parenchymal hypotrophy and/or deviation of the medial line structures (Table 1, Figure 1).

Table 1. Macroscopic analysis of encephala from BALB/c WT and BALB/c IL-4-KO mice experimentally infected with Taenia crassiceps cysticerci.

\begin{tabular}{|c|c|c|c|c|c|c|c|c|}
\hline \multirow{2}{*}{ Variables } & \multicolumn{2}{|c|}{$07 \mathrm{DPI}$} & \multicolumn{2}{|c|}{$30 \mathrm{DPI}$} & \multicolumn{2}{|c|}{$60 \mathrm{DPI}$} & \multicolumn{2}{|c|}{$90 \mathrm{DPI}$} \\
\hline & WT & IL-4-KO & WT & IL-4-KO & WT & IL-4-KO & WT & IL-4-KO \\
\hline Location of cysticerci & LV & $\mathrm{LV} / 3^{\text {rd }} \mathrm{V}$ & LV & LV & LV & LV & LV & LV \\
\hline Edema & + & ++ & + & + & + & + & + & + \\
\hline Ventriculomegaly & + & + & + & ++ & ++ & ++ & +++ & +++ \\
\hline
\end{tabular}

WT: Wild type; IL-4-KO: IL-4 knockout gene; DPI: days post infection; -: absent; +: discrete; ++: moderate; +++: accentuated; LV: lateral ventricle; 3 rd $V$ : third ventricle; $n=5$ per each experimental day.
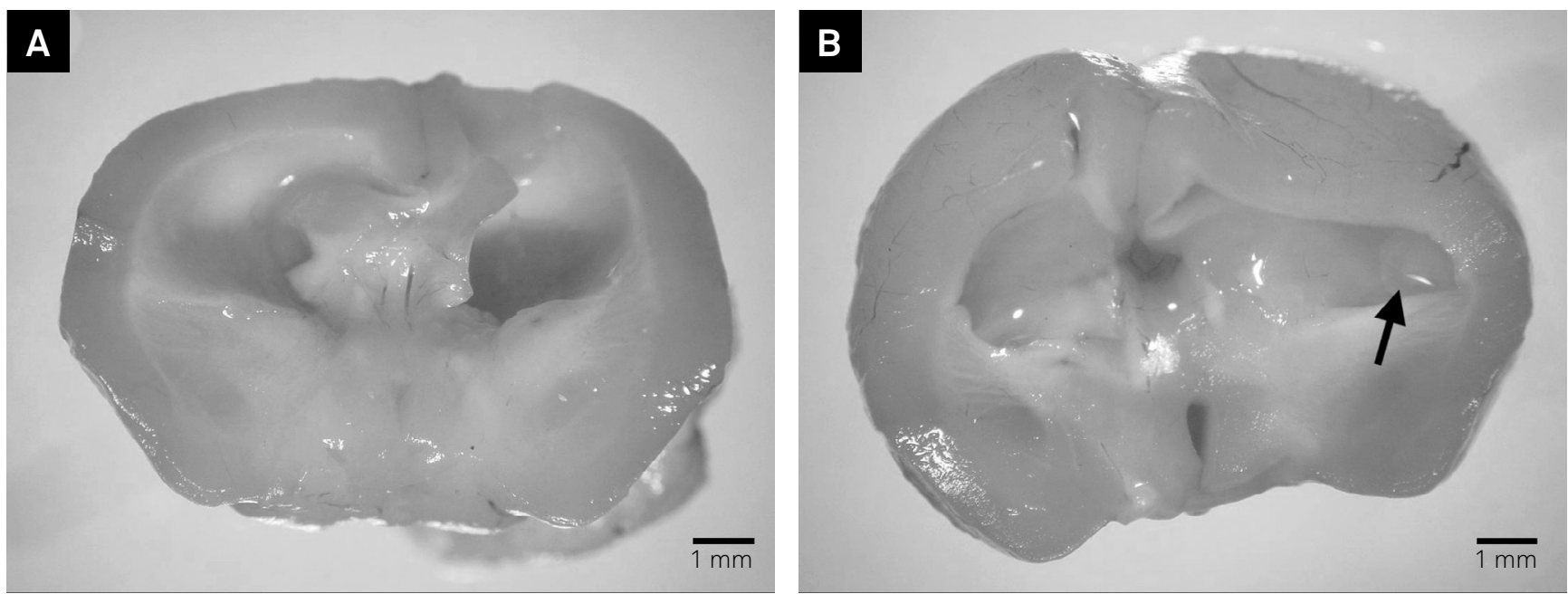

Figure 1. Mesoscopy of BALB/c WT (A) and IL-4-KO BALB/c (B) encephala showing ventriculomegaly and deviation of the medial line. It is possible to observe a cysticercus (arrow) inside the ventricle (scale bar $=1 \mathrm{~mm}$ ). 


\section{Cysticerci location and classification}

When analyzing all the infected $\mathrm{BALB} / \mathrm{c}$ animals, it was possible to visualize the cysticerci in $60 \%(\mathrm{n}=24)$. In BALB/c WT animals these occurred in $20 \%(n=4)$ of the infected animals, while in BALB/c IL-4-KO infected animals the rate of cysticerci observation was $100 \%(n=20)$. Also, $25 \%$ $(n=5)$ of BALB/c IL-4-KO infected animals showed more than one cysticercus in the encephala.

Regarding the cysticerci evolutionary stage classification, it was possible to observe initial stage parasites at seven DPI, in both mice lineages. At 30 DPI, BALB/c WT animals showed initial stage cysticerci while BALB/c IL-4-KO animals showed larval stage ones. At 60 DPI, both lineages showed larval stage cysticerci. Finally, at 90 DPI, $\mathrm{BALB} / \mathrm{c}$ WT animals showed final stage cysticerci, while in $\mathrm{BALB} / \mathrm{c}$ IL-4-KO animals both larval and final stage cysticerci were observed.

As to location, most of the parasites were observed in the lateral ventricles (Table 1).

\section{Host tissue response}

At seven DPI, the BALB/c IL-4-KO animals showed increased parenchymal inflammatory infiltration of mononuclear cells surrounding the parasite (Table 2, Figures 2A, 2B), gliosis (Figure $2 \mathrm{C}$ ) and meningitis when compared to BALB/C WT animals $(\mathrm{p}<0.05)$. While the BALB/c WT animals showed an intraventricular cysticercus with inflammatory infiltration of mononuclear cells in the host tissue (Figure 2D).

At60 DPI, BALB/cWT animals showed higher inflammatory infiltration of polymorphonuclear cells and hyperemia when compared to BALB/c IL-4-KO animals ( $p<0.05)$. In BALB/c WT animals, it was possible to observe an inflammatory infiltration of mononuclear cells inside the ventricles (Figure 2E).

At 90 DPI, BALB/c IL-4-KO animals showed higher hyperemia and meningitis when compared to BALB/c WT animals $(\mathrm{p}<0.05)$ (Figure 2F).

The control group animals from both lineages showed hyperemia and edema in discrete intensity in the first days after the inoculation of saline sterile solution.

Table 2. Histopathologic analysis of host tissue from encephala of BALB/c WT and BALB/C IL-4-KO mice infected with Taenia crassiceps cysticerci. Results in mean \pm standard deviation.

\begin{tabular}{|c|c|c|c|c|}
\hline Microscopic alterations & DPI & BALB/c WT & BALB/c IL-4-KO & $\mathrm{p}$ \\
\hline \multirow{4}{*}{ PMN cells inflammatory infiltration } & 7 & $1.6 \pm 0.89$ & $1.0 \pm 0.0$ & $p>0.05$ \\
\hline & 30 & $1.8 \pm 0.44$ & $1.6 \pm 0.89$ & $p>0.05$ \\
\hline & 60 & $2.6 \pm 0.54$ & $1.2 \pm 0.83$ & $p=0.014^{*}$ \\
\hline & 90 & $1.2 \pm 0.44$ & $1.6 \pm 0.54$ & $p>0.05$ \\
\hline \multirow{4}{*}{ MN cells inflammatory infiltration } & 7 & $1.0 \pm 0.0$ & $1.8 \pm 0.44$ & $p=0.032 *$ \\
\hline & 30 & $1.4 \pm 0.54$ & $1.2 \pm 0.44$ & $p>0.05$ \\
\hline & 60 & $1.6 \pm 0.54$ & $1.2 \pm 0.83$ & $p>0.05$ \\
\hline & 90 & $1.4 \pm 0.54$ & $1.6 \pm 0.54$ & $p>0.05$ \\
\hline \multirow{4}{*}{ Perivasculitis } & 7 & $1.6 \pm 0.54$ & $0.6 \pm 0.89$ & $p>0.05$ \\
\hline & 30 & $1.6 \pm 0.54$ & $1.6 \pm 0.54$ & $p>0.05$ \\
\hline & 60 & $1.8 \pm 0.83$ & $1.2 \pm 0.83$ & $p>0.05$ \\
\hline & 90 & $1.0 \pm 0.70$ & $2.4 \pm 0.54$ & $p>0.05$ \\
\hline \multirow{4}{*}{ Hyperemia } & 7 & $1.6 \pm 0.54$ & $1.6 \pm 0.54$ & $p>0.05$ \\
\hline & 30 & $1.6 \pm 0.54$ & $1.4 \pm 0.54$ & $p>0.05$ \\
\hline & 60 & $2.4 \pm 0.54$ & $1.2 \pm 0.44$ & $P=0.016^{*}$ \\
\hline & 90 & $1.2 \pm 0.44$ & $2.2 \pm 0.44$ & $P=0.032 *$ \\
\hline \multirow{4}{*}{ Gliosis } & 7 & $0.0 \pm 0.0$ & $1.4 \pm 0.54$ & $P=0.008^{*}$ \\
\hline & 30 & $2.4 \pm 0.89$ & $1.6 \pm 0.89$ & $p>0.05$ \\
\hline & 60 & $0.6 \pm 0.89$ & $1.2 \pm 1.30$ & $p>0.05$ \\
\hline & 90 & $0.8 \pm 0.44$ & $1.2 \pm 0.44$ & $p>0.05$ \\
\hline \multirow{4}{*}{ Meningitis } & 7 & $0.2 \pm 0.44$ & $1.4 \pm 0.54$ & $P=0.032 \star$ \\
\hline & 30 & $1.4 \pm 0.54$ & $1.6 \pm 0.89$ & $p>0.05$ \\
\hline & 60 & $2.4 \pm 0.89$ & $1.2 \pm 0.83$ & $p>0.05$ \\
\hline & 90 & $0.4 \pm 0.54$ & $1.8 \pm 0.83$ & $P=0.014^{*}$ \\
\hline \multirow{4}{*}{ Ependymitis } & 7 & $1.2 \pm 0.44$ & $1.0 \pm 0.0$ & $p>0.05$ \\
\hline & 30 & $0.8 \pm 0.44$ & $1.2 \pm 0.44$ & $p>0.05$ \\
\hline & 60 & $1.0 \pm 0.0$ & $0.8 \pm 0.44$ & $p>0.05$ \\
\hline & 90 & $1.0 \pm 0.70$ & $1.0 \pm 0.0$ & $p>0.05$ \\
\hline
\end{tabular}

DPI: days post inoculation; PMN: polymorphonuclear cells; MN: mononuclear cells; BALB/c: BALB mice; WT: wild type; IL-4-KO: IL-4 - Knockout; ${ }^{\star}$ statistical difference. 


\section{DISCUSSION}

Helminths such as T. crassiceps cysticerci have developed complex mechanisms to evade or modulate the host response during infection. This study describes the influence of an important cytokine such as IL-4 in response to helminthic infection. The use of genetically modified mice lineages is an important tool in the understanding of the host-parasite relationship to the development of the parasitic infection and, consequently, the clinical manifestations of the infection?

All the infected animals showed both micro- and macroscopic alterations, even when the cysticerci were not visible on macroscopic analysis. All the control animals showed discrete levels of edema and hyperemia due to the mechanical trauma of the inoculation of sterile saline solution. These discrete alterations in the control group have also been observed in other experimental NCC studies ${ }^{6,13,18,21}$.

In the infected animals, the majority of the cysticerci were located inside the lateral ventricles accompanied by a discrete-to-moderate intensity of inflammatory response. This fact was previously reported in studies that showed that the mere presence of the parasite's antigens are responsible for the development of inflammatory alterations and ventriculomegaly, which may lead to cerebrospinal fluid obstruction ${ }^{22,23}$. Zepeda et al. ${ }^{21}$ showed that $T$. crassiceps antigens are able to induce inflammation
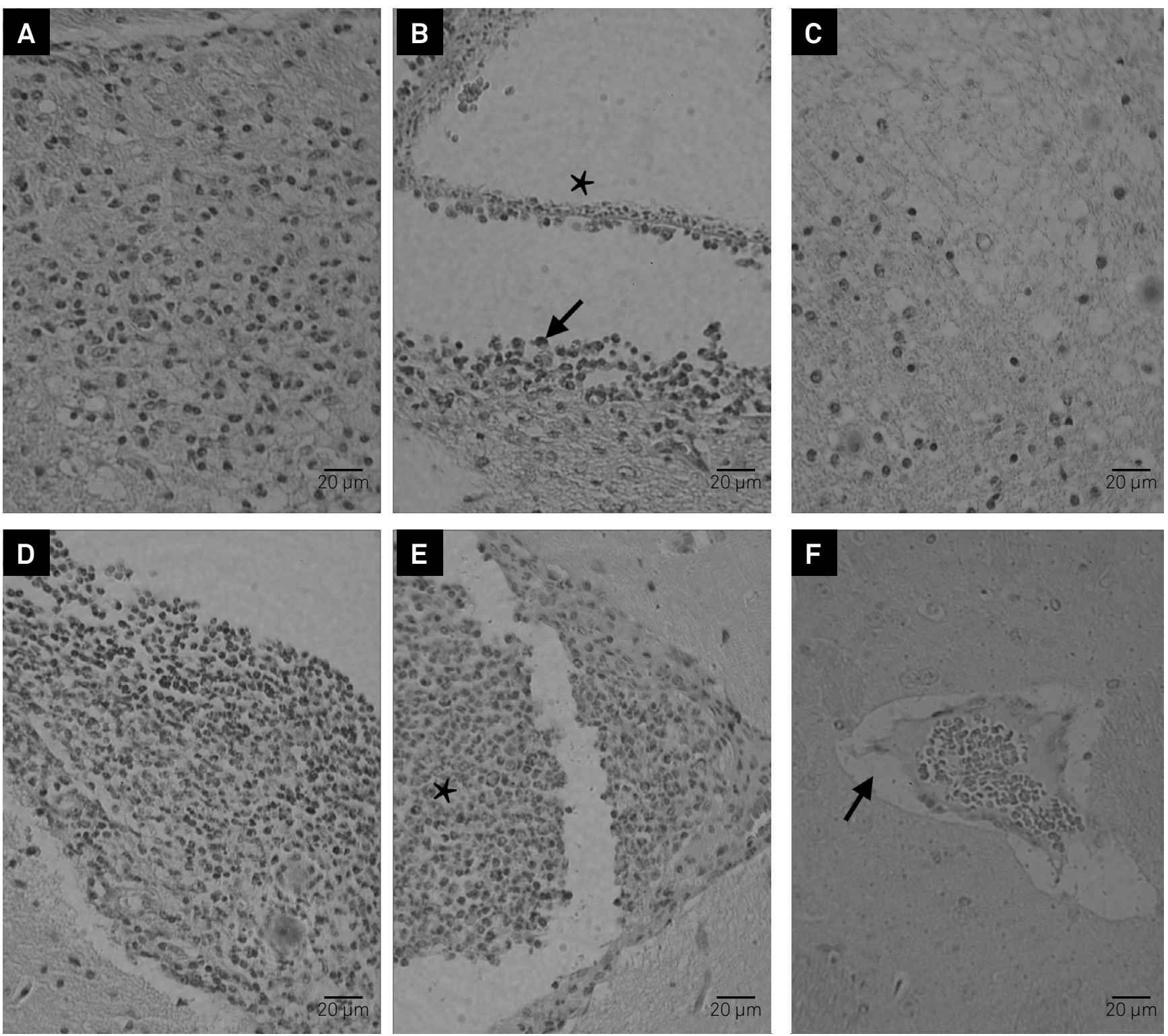

Figure 2. Microscopic alterations in encephala of intracranial infected BALB/c WT and BALB/c IL-4-KO mice. (A-F) hematoxilin-eosin stain, scale bar $=20 \mu \mathrm{m}$. (A) parenchymal mononuclear cells inflammatory infiltration at seven days post-inoculation (DPI) in BALB/c IL-4-KO; (B) Intraventricular viable cysticercus (asterisk) and mononuclear cell inflammatory infiltration (arrow) in the host tissue at seven DPI in BALB/c WT; (C) Gliosis, at seven DPI in BALB/c IL-4-KO; (D) meningitis at 90 DPI in BALB/c IL-4-KO; (E) intraventricular polymorphonuclear cell inflammatory infiltration (asterisk) at 60 DPI in BALB/c WT; (F) hyperemia and perivascular edema (arrow) at $90 \mathrm{DPI}$ in $\mathrm{BALB} / \mathrm{C} \mathrm{LL}-4-\mathrm{KO}$. 
in the brain tissue and apoptosis of hippocampal cells. Histological studies have shown that viable cysticerci, such as the ones in our study, have little or no surrounding inflammation in humans and pigs; while degenerating or dead cysticerci, which were not found in our study, had an inflammatory response in their surroundings ${ }^{24}$.

In our study, all infected animals showed ependymitis, meningitis and perivasculitis. These alterations have also been described in experimental NCC in rats ${ }^{19}$. In our study, it was not possible to observe calcification of the cysticerci, or in the surrounding host tissue. However, the calcification of the cysticerci and host tissue was observed in autopsies of human intraventricular $\mathrm{NCC}^{25}$ and in a swine model of $\mathrm{NCC}^{2}$, probably because the material analyzed had a longer time of infection.

The initial stage cysticerci showed a discrete intensity of inflammatory infiltration surrounding the parasite. As the cysticerci die, the immune modulation is lost, resulting in an increase in the inflammatory intensity accompanied by fibrosis. Alvarez et al., ${ }^{5}$ studying experimental NCC, reported that the parasite initiates the immunomodulation through complex glycoproteins present in the tegument surface resulting in the viability of the parasite. The histopathologic analysis of human asymptomatic NCC shows viable cysticerci surrounded by discrete or absent inflammatory infiltration that contributes to the chronicity of the infection ${ }^{25}$. On the other hand, Fleury et al. ${ }^{25}$, studying cysticerci removed from human NCC, reported that the parasite is surrounded by human immunoglobulin such as IgG, IgM, IgA and IgE, which act as a kind of camouflage due to the presence of Fc receptors in the parasite tegument surface.

In BALB/c WT animals it was possible to observe that the peak evolution of the encephalitis was accompanied by a partial destruction of the cysticerci in the experimental days. In the BALB/c IL-4-KO animals, the evolution of the inflammatory process was not resolved due to the presence of viable cysticerci until the end of the experimental days. The absence of IL-4 resulted in difficulty in controlling the parasitic infection. A Th1 immune response is observed while the parasite is still viable, while a mixed Th1/Th2 immune response is observed when the parasite is being destroyed ${ }^{26}$. Experimental NCC studies have shown an inflammatory infiltration of macrophages and plasmocytes in the high levels of tissue IL- $4^{25}$ in rats and pigs. These findings show that the parasite maintains an equilibrium with the host immune response at the beginning of the infection and therefore a rapid Th1 response is observed, leading to the production of IgG. However, as the infection progresses the balance is modified to a mixed Th1/Th2 response, which may result in destruction of the cysticerci ${ }^{27}$.

When mononuclear cells from human asymptomatic NCC patients are stimulated in vitro, it is possible to observe the increased production of IL-4, IL-5 and IL-13, which are Th2 cytokines ${ }^{27}$. However, when the mononuclear cells are collected from symptomatic NCC patients, the profile of the cytokines produced are quite different, with a predominance of IFN-gamma, IL-17, IL-23 and TNF-alpha, which are from the Th2 profile ${ }^{24}$. Asymptomatic NCC patients from endemic areas have shown a Th2 response with production of IgG4, IL-4, IL-5 and IL- $13^{27}$.

In the M. corti experimental NCC model, it was observed that the Th1 immune profile was related to a strong immune response capable of destruction of the parasite and tissue injury ${ }^{13}$. Matos-Silva et al. ${ }^{6}$ also found similar results using the T. crassiceps NCC model. Using the same model, Moura et al..$^{18}$ described a predominance of the Th2 immune profile cytokines at the end of the infection, while in the acute phase of the infection there was a mixed Th1/Th17 profile accompanied by high levels of IL-10.

$\mathrm{BALB} / \mathrm{c}$ animals are naturally susceptible to $T$. crassiceps infection, both in the intraperitoneal and intracranial locations, due to its natural development of a Th2 profile response ${ }^{7,28}$. The main cytokine of the Th2 profile is IL- 4 as it induces activation and effectiveness of $\mathrm{T}$ lymphocytes and also stimulates the change of lymphocyte B isotype into IgE production. As well, IL-4 suppresses the IFN-gamma activity of macrophages resulting in the inhibition of these cells ${ }^{7,26}$.

Therefore an immune Th2 response, which is considered protective against intestinal helminthic infections, is harmful to the host when it favors the establishment and growth of tissue helminthes ${ }^{26}$. Greater parasitic burden was observed in Th2 immune profile animals studied by Rodrigues-Sosa et al. ${ }^{26}$, as well as in our findings in which we observed cysticerci in all BALB/c IL-4-KO infected animals.

In central nervous system infections, IL-4 plays an important role in the immune regulation due to stimulation and chemotaxis of eosinophils, mastocytes, basophils and other Th2 profile cells. Also, the survival of these cells are maintained by the influence of IL- $4{ }^{29}$. Experimental studies have shown the influence of this cytokine as a neuroprotective factor on astrocytes and microglia ${ }^{29,30}$. Falcone et al. ${ }^{30}$, studying an experimental model of autoimmune encephalitis in IL-4-KO mice, reported that the animals without IL-4 showed a more severe form of clinical disease, with extensive involvement of spinal cord accompanied by increased production of pro-inflammatory cytokines.

According to the anatomopathological findings and the analysis of the inflammatory process in the infected animals, it is possible to conclude that the absence of IL-4 induced less intense inflammatory alterations. This response probably retarded the destruction of the cysticerci, leading to a greater parasitic burden, tissue destruction and chronicity of the infection. 
1. Cantey PT, Coyle CM, Sorvillo FJ, Wilkins PP, Starr MC, Nash TE. Neglected parasitic infections in the United States: cysticercosis. Am J Trop Med Hyg. 2014;90(5):805-9. http://doi.org/10.4269/ajtmh.13-0724

2. Nash TE. Parasitic diseases that cause seizures. Epilepsy Curr. 2014;14(1 suppl):29-34. http://doi.org/10.5698/1535-7511-14.s2.29

3. Del Brutto $\mathrm{OH}$. Neurocysticercosis among international travelers to disease-endemic areas. J Travel Med. 2012;19(2):112-7. http://doi.org/10.1111/j.1708-8305.2011.00592.x.

4. Garcia HH, Rodriguez S, Gilman RH, Gonzalez AE, Tsang VC. Neurocysticercosis: is serology useful in the absence of brain imaging? Trop Med Int Health. 2012;17(8):1014-8. http://doi.org/10.1111/j.1365-3156.2012.03037.x

5. Alvarez JI, Mishra BB, Gundra UM, Mishra PK, Teale JM. Mesocestoides corti intracranial infection as a murine model for neurocysticercosis. Parasitology. 2010;137(3):359-72. http://doi.org/10.1017/S0031182009991971

6. Matos-Silva H, Reciputti BP, Paula EC, Oliveira AL, Moura VB, Vinaud MC et al. Experimental encephalitis caused by Taenia crassiceps cysticerci in mice. Arq Neuropsiq. 2012;70(4):287-92. http://doi.org/10.1590/S0004-282X2012005000010

7. Terrazas LI The complex role of pro- and anti-inflammatory cytokines in cysticercosis: immunological lessons from experimental and natural hosts. Curr Top Med Chem. 2008;8(5):383-92. http://doi.org/10.2174/156802608783790848

8. Vaz AJ, Nunes CM, Piazza RM, Livramento JA, Da Silva MV, Nakamura PM et al. Immunoblot with cerebrospinal fluid from patients with neurocysticercosis using antigen from cysticerci of Taenia solium and Taenia crassiceps. Am J Trop Med Hyg. 1997;57(3):354-7.

9. Fragoso G, Lamoyi E, Mellor A, Lomeli C, Hernández M, Sciutto E. Increased resistance to Taenia crassiceps murine cysticercosis in Qa-2 transgenic mice. Infect Immun. 1998;66(2):760-4.

10. Villa OF, Kuhn RE. Mice infected with the larvae of Taenia crassiceps exhibit a Th2-like immune response with concomitant anergy and downregulation of Th1-associated phenomena. Parasitology. 1996;112(6):561-70. http://doi.org/10.1017/S0031182000066142

11. Terrazas LI, Bojalil R, Govezensky T, Larralde C. Shift from an early protective Th1-type immune response to a late permissive Th2-type response in murine cysticercosis (Taenia crassiceps). J Parasitol. 1998;84(1):74-81. http://doi.org/10.2307/3284533

12. Toenjes SA, Spolski RJ, Mooney KA, Kuhn RE. The systemic immune response of BALB/c mice infected with larval Taenia crassiceps is a mixed Th1/Th2-type response. Parasitology. 1999;118(6):623-33. http://doi.org/10.1017/S0031182099004370

13. Cardona AE, Restrepo BI, Jaramillo JM, Teale JM. Development of an animal model for neurocysticercosis: immune response in the central nervous system is characterized by a predominance of gamma delta T cells. J Immunol. 1999;162(2):995-1002.

14. Alvarez JI, Teale JM. Differential changes in junctional complex proteins suggest the ependymal lining as the main source of leukocyte infiltration into ventricles in murine neurocysticercosis. J Neuroimmunol. 2007;187(1-2):102-13. http://doi.org/10.1016/j.jneuroim.2007.05.005

15. Abraham R, Pardini AX, Vaz AJ, Livramento JA, Machado LR. Taenia antigens detection in the cerebrospinal fluid of patients with neurocysticercosis and its relationship with clinical activity of the disease. Arq Neuropsiquiatr. 2004;62(3B):756-60. http://doi.org/10.1590/S0004-282X2004000500002
16. Heldwein K, Biedermann HG, Hamperl WD, Bretzel G, Löscher T, Laregina D et al. Subcutaneous Taenia crassiceps infection in a patient with non-Hodgkin's lymphoma. Am J Trop Med Hyg. 2006;75(1):108-11.

17. Ntoukas V, Tappe D, Pfütze D, Simon M, Holzmann T. Cerebellar cysticercosis caused by larval Taenia crassiceps tapeworm in immunocompetent woman, Germany. Emerg Infect Dis. 2013;19(12):2008-11. http://doi.org/10.3201/eid1912.130284

18. Moura VB, Lima SB, Matos-Silva H, Vinaud MC, Loyola PR, Lino RS. Cellular immune response in intraventricular experimental neurocysticercosis. Parasitology. 2016;143(3):334-42. http://doi.org/10.1017/S0031182015001572

19. Verastegui MR, Mejia A, Clark T, Gavidia CM, Maman $J$, Ccopa F et al. Novel rat model for neurocysticercosis using Taenia solium. Am J Pathol. 2015;185(8):2259-68. http://doi.org/10.1016/j.ajpath.2015.04.015

20. Fleury A, Trejo A, Cisneros H, García-Navarrete R, Villalobos N, Hernández $\mathrm{M}$ et al. Taenia solium: development of an experimental model of porcine neurocysticercosis. PLoS Negl Trop Dis. 2015;9(8):e0003980. http://doi.org/10.1371/jornal.pntd.0003980

21. Zepeda N, Solano S, Copitin N, Chávez JL, Fernández AM, García F et al. Apoptosis of mouse hippocampal cells induced by Taenia crassiceps metacestode factor. J Helminthol. 2016 Mar 28. http://doi.org/10.1017/S0022149X16000146

22. Amelot A, Faillot T. Hydrocephalus and neurocysticercosis: cases illustrative of three distinct mechanisms. J Clin Neurol. 2014;10(4):363-6. http://doi.org/10.3988/jcn.2014.10.4.363

23. Garcia HH, Nash TE, Del Brutto OH. Clinical symptoms, diagnosis, and treatment of neurocysticercosis. Lancet Neurol. 2014;13(12):1202-15. http://doi.org/10.1016/S1474-4422(14)70094-8

24. Singh SK, Prasad KN. Immunopathogenesis of Neurocysticercosis: Role of cytokines. Immunome Res. 2015;11(2):96. http://doi.org/10.4172/1745-7580.1000096

25. Fleury A, Cardenas G, Adalid-Peralta L, Fragoso G, Sciutto E. Immunopathology in Taenia solium neurocysticercosis. Parasite Immunol. 2016;38(3):147-57. http://doi.org/10.1111/pim.12299

26. Rodriguez-Sosa M, David JR, Bojalil R, Satoskar AR, Terrazas LI. Cutting edge: susceptibility to the larval stage of the helminth parasite Taenia crassiceps is mediated by Th2 response induced via STAT6 signaling. J Immunol. 2002;168(7):3135-9. http://doi.org/10.4049/jimmunol.168.7.3135

27. Chavarría A, Roger B, Fragoso G, Tapia G, Fleury A, Dumas $\mathrm{M}$ et al. $\mathrm{TH} 2$ profile in asymptomatic Taenia solium human neurocysticercosis. Microbes Infect. 2003;5(12):1109-15. http://doi.org/10.1016/S1286-4579(03)00206-5

28. Freitas AA, Moura VB, Gonçalves SF, Rodrigues AA, Félix RM, Soares TP et al. Kinetics of the inflammatory response in subcutaneous cysticercosis induced in mice by Taenia crassiceps. J Comp Pathol. 2012;147(2-3):267-74. http://doi.org/10.1016/j.jcpa.2011.12.009

29. Gadani SP, Cronk JC, Norris GT, Kipnis J. IL-4 in the brain: a cytokine to remember. J Immunol. 2012;189(9):4213-9. http://doi.org/10.4049/jimmunol.1202246

30. Falcone M, Rajan AJ, Bloom BR, Brosnan CF. A critical role for $\mathrm{IL}-4$ in regulating disease severity in experimental allergic encephalomyelitis as demonstrated in IL-4-deficient C57BL/6 mice and BALB/c mice. J Immunol. 1998;160(10):4822-30. 